\title{
Tricuspid regurgitation velocity and other biomarkers of mortality in children, adolescents and young adults with sickle cell disease in the United States: The PUSH study
}

\author{
Mehdi Nouraie $^{1}$ | Deepika S. Darbari ${ }^{2}$ (1) | Sohail Rana ${ }^{3}$ | Caterina P. Minniti ${ }^{4}$ (ㅇ | \\ Oswaldo L. Castro $^{3}$ | Lori Luchtman-Jones ${ }^{5}$ | Craig Sable ${ }^{2}$ | Niti Dham ${ }^{2}$ | \\ Gregory J. Kato ${ }^{1}$ (1) | Mark T. Gladwin ${ }^{1}$ | Gregory Ensing ${ }^{6}$ | Manuel Arteta ${ }^{7}$ | \\ Andrew Campbell ${ }^{2}$ (i) | James G. Taylor $\mathrm{VI}^{3}$ (]) | Sergei Nekhai ${ }^{3}$ (i) |
}

Victor R. Gordeuk ${ }^{8}$ ๑

${ }^{1}$ University of Pittsburgh, Pittsburgh, Pennsylvania

${ }^{2}$ Children's National Medical Center, Washington, District of Columbia

${ }^{3}$ Center for Sickle Cell Disease, Howard University, Washington, District of Columbia

${ }^{4}$ Montfiore Medical Center, Einstein College of Medicine, New York, New York

${ }^{5}$ Cincinnati Children's Hospital Medical Center/University of Cincinnati College of Medicine, Cincinnati, Ohio

${ }^{6}$ University of Michigan, Ann Arbor, Michigan

${ }^{7}$ Mayo Clinic, Rochester, Minnesota

${ }^{8}$ University of Illinois at Chicago, Chicago, Illinois

Correspondence

Mehdi Nouraie, University of Pittsburgh,

Pittsburgh, PA.

Email: nouraies@upmc.edu

Deepika S. Darbari, Children's National

Medical Center, Washington, DC.

Email: ddarbari@childrensnational.org

Victor R. Gordeuk, University of Illinois at

Chicago, Chicago, IL.

Email:vgordeuk@uic.edu

Funding information

This study was supported by 2 R 25 HL003679-08, 1 P5OHL118006 and 1 R01 HL079912-02 from NHLBI/NIH, by Howard University GCRC grant 2MOI RR10284-10 from NCRR/NIH, and by the intramural research program of the National Institutes of Health

\begin{abstract}
In the US, mortality in sickle cell disease (SCD) increases after age 18-20 years. Biomarkers of mortality risk can identify patients who need intensive follow-up and early or novel interventions. We prospectively enrolled 510 SCD patients aged 3-20 years into an observational study in 2006-2010 and followed 497 patients for a median of 88 months (range 1-105). We hypothesized that elevated pulmonary artery systolic pressure as reflected in tricuspid regurgitation velocity (TRV) would be associated with mortality. Estimated survival to 18 years was $99 \%$ and to 25 years, $94 \%$. Causes of death were known in seven of 10 patients: stroke in four (hemorrhagic two, infarctive one, unspecified one), multiorgan failure one, parvovirus B19 infection one, sudden death one. Baseline TRV $\geq 2.7 \mathrm{~m} /$ second ( $>2 \mathrm{SD}$ above the mean in age-matched and gendermatched non-SCD controls) was observed in $20.0 \%$ of patients who died vs $4.6 \%$ of those who survived ( $P=.012$ by the log rank test for equality of survival). The baseline variable most strongly associated with an elevated TRV was a high hemolytic rate. Additional biomarkers associated with mortality were ferritin $\geq 2000 \mu \mathrm{g} / \mathrm{L}$ (observed in $60 \%$ of patients who died vs $7.8 \%$ of survivors, $P<.001$ ), forced expiratory volume in 1 minute to forced vital capacity ratio (FEV1/FVC) $<0.80$ (71.4\% of patients who died vs $18.8 \%$ of survivors, $P<.001)$, and neutrophil count $\geq 10 \times 10^{9} / \mathrm{L}$ (30.0\% of patients who died vs $7.9 \%$ of survivors, $P=.018$ ). In SCD children, adolescents and young adults, steady-state elevations of TRV, ferritin and neutrophils and a low FEV1/FVC ratio may be biomarkers associated with increased risk of death.
\end{abstract}




\section{1 | INTRODUCTION}

Sickle cell disease (SCD) is one of the most common monogenic diseases in the United States and worldwide. Characterized by the homozygous Glu6Val mutation in HBB, the beta-globin gene, SCD is associated with progressive multisystem organ damage and early mortality. In recent decades, interventions such as newborn screening, penicillin prophylaxis, immunizations, screening for risk of stroke with transcranial Doppler, and disease-modifying therapies such as hydroxyurea and chronic blood transfusion have led to a decline in mortality and morbidity for children and adolescents with SCD, especially those living in developed countries. ${ }^{1}$ A Dallas, TX cohort study of 711 newborns diagnosed with sickle cell anemia between 1983 and 2007 reported that $95 \%$ survived the first decade of life and that the patterns of mortality are evolving. ${ }^{2}$ Mortality increases in adolescents and young adults after transition to adult care had causes including acute chest syndrome, multi-organ failure syndrome, sepsis and other complications. ${ }^{3,4}$ Studies of SCD cohorts from Europe have reported sepsis, stroke and acute anemia as the leading causes of mortality in children with SCD. ${ }^{1,5-7}$

Despite advances in care, mortality in children, adolescents and young adults with SCD in the US continues to be unacceptably high. In one recent US study, mortality up to age 18 years was $6.1 \%$ in patients with sickle cell anemia and $1.6 \%$ with milder forms of SCD. ${ }^{3}$ It is important to identify young patients at high risk of death so that early interventions can be developed to reduce this high mortality. The goal of the present analysis was to determine the frequency and causes of death in a prospective, multi-institutional contemporary cohort of children, adolescents and young adults with SCD and to determine biomarkers associated with mortality in this cohort.

\section{2 | METHODS}

The Pulmonary Hypertension and the Hypoxic Response study (PUSH) is a multi-institutional observational investigation that prospectively followed a cohort of children, adolescents and young adults with SCD. The study postulated that elevated systolic pulmonary pressure as reflected in an elevated tricuspid regurgitation velocity (TRV) would be a risk factor for mortality.

\subsection{Clinical evaluation of SCD patients and controls}

The study enrolled 510 patients with SCD and 75 control subjects 3 to 20 years of age from 2006 to 2010 at four institutions. The institutional review boards of all four participating institutions approved the study protocol. The subjects and/or their parent or legal guardian provided written informed consent to participate in accordance with the Declaration of Helsinki. The trial is registered with clinicaltrial.gov (NCT00495638). The controls were matched by age, sex and ethnicity to approximately every sixth patient enrolled. SCD was confirmed by hemoglobin electrophoresis, high performance liquid chromatography or genetic analysis in some cases. The SCD patients were invited to participate on a consecutive basis, as they presented for routine outpatient care; no attempt was made to select them by known or perceived risk factors. Before enrollment, at least 3 weeks had elapsed since hospitalization, emergency department or clinic visit for a pain crisis, acute chest syndrome, infection or other SCD related complication. ${ }^{8}$ Baseline clinical assessments including routine blood work, echocardiography and pulmonary function testing were performed. ${ }^{8-13}$ Standardized medical history forms that included questions regarding stroke, asthma and blood transfusions were filled out by a clinical research nurse who interviewed the patient or a parent and confirmed the findings by discussion with the patient's physician and by chart review. At the time of enrollment in PUSH, it was the policy of all participating institutions to perform transcranial Doppler (TCD) screening on all eligible SCD patients. Follow-up for survival was available for 497 of the participants at a median of 88 months (range of 1-105 months) after enrollment.

\section{2 | Definition of cutoff values for biomarkers}

A TRV $\geq 2.7 \mathrm{~m} /$ second is more than $2 \mathrm{SD}$ above the mean value in the non-SCD controls in this study as described in the results section. A serum ferritin of $\geq 2000 \mu \mathrm{g} / \mathrm{L}$ was used to define transfusional iron overload in SCD patients by the Multi-Center Iron Overload Research Group. ${ }^{14} \mathrm{~A}$ forced expiratory volume in 1 minute to forced vital capacity ratio (FEV1/FVC) $<80 \%$ has been used to define pathological airway obstruction in childhood asthma. ${ }^{15,16}$ An absolute neutrophil count $\geq 10 \times 10^{9}$ per liter is a cut-off that suggests the possibility of a bacterial infection in otherwise healthy children and adolescents. ${ }^{17} \mathrm{~N}$-terminal pro-brain natriuretic peptide (NT-proBNP) $\geq 160 \mathrm{ng} / \mathrm{L}$ has been used to define an elevated value in numerous previous studies. ${ }^{18-21}$ Hemoglobin oxygen saturation $\leq 95 \%$ has been suggested to identify SCD children at risk for hypoxia. ${ }^{22}$ Glomerular filtration rate (GFR) $<90 \mathrm{~mL} /$ minutes $/ 1.73 \mathrm{~m}^{2}$ is the cutoff that defines Stage I decline in GFR by Kidney Disease: Improving Global Outcomes (KDIGO) guidelines. ${ }^{23}$ Systolic blood pressure $>115 \mathrm{mmHg}$ is the cut-off that requires further evaluation or intervention in early adolescents. ${ }^{24} \mathrm{~A}$ left atrial diameter $\geq 3.68 \mathrm{~cm}$, a lateral transmitral Doppler early filling velocity to tissue Doppler early diastolic mitral annular velocity $\left(E / e^{\prime}\right)$ ratio $\geq 8.84$, and a left ventricular internal diameter in diastole (LVIDD) z-score $\geq 1.8$ are more than 2 SD above mean values in the non-SCD controls of this study.

\section{3 | Statistical analysis}

We applied principal component analysis to create a hemolytic component from age and site-adjusted values of aspartate amino transferase 
(AST), lactate dehydrogenase (LDH), total bilirubin and reticulocyte count. Statistical comparisons were made using the Fisher exact test for categorical variables and the Student $t$ test for continuous variables (with normally transformed data). The independent relationship of serum ferritin concentration with baseline variables was assessed with multiple linear regression. The survival of patients over the study period was calculated by Kaplan-Meier estimate. The association of historical variables and biomarkers with mortality was determined by the log rank test for equality of survivor function. We did not perform multi-variate analysis of mortality using the identified risk factors because there were too few deaths to justify this approach. Analyses were performed in Stata 15.0 (StataCorp, College Station, TX).

\section{3 | RESULTS}

\subsection{Comparison of SCD patients and controls}

The genotypes of the 497 SCD patients with follow-up information were $\mathrm{HbSS}$ in 372 (74.8\%), $\mathrm{HbSC}$ in 91 (18.4\%), $\mathrm{Hb} \mathrm{S} \beta^{+}$-thalassemia in

TAB LE 1 Clinical characteristics of SCD patients and controls. Results expressed in median and interquartile range unless otherwise indicated. Statistical comparison by $t$ test or Fisher's exact test

\begin{tabular}{|c|c|c|c|c|c|}
\hline & $\mathrm{N}$ & SCD & $\mathrm{N}$ & Controls & $P$ \\
\hline \multicolumn{6}{|l|}{ Demographics and genetics } \\
\hline Age (years) & 497 & $12(7-16)$ & 75 & $14(9-17)$ & .021 \\
\hline Alpha-thalassemia in no. (\%) & 466 & & 66 & & .5 \\
\hline No alpha-globin gene deletion & & $316(67.5 \%)$ & & 47 (71.2\%) & \\
\hline Single alpha-globin deletion & & $138(29.5 \%)$ & & $19(28.8 \%)$ & \\
\hline \multicolumn{6}{|l|}{ Medical history } \\
\hline Asthma & 493 & 119 (24.1\%) & 75 & 14 (18.7\%) & .38 \\
\hline Stroke & 492 & $52(10.6 \%)$ & 75 & 0 & .001 \\
\hline Acute chest syndrome or pneumonia & 492 & $239(48.6 \%)$ & 75 & $2(2.7 \%)$ & $<.001$ \\
\hline \multicolumn{6}{|l|}{ Physical examination } \\
\hline \multicolumn{6}{|l|}{ Echocardiogram and PFT } \\
\hline Tricuspid regurgitation velocity $(\mathrm{m} / \mathrm{sec})$ & 441 & $2.3(2.1-2.5)$ & 67 & $2.1(2.0-2.3)$ & $<.0001$ \\
\hline Left ventricular internal diameter $\mathrm{z}$ score & 469 & $1.3(0.2-2.2)$ & 71 & $-0.5(-1.3-0.1)$ & $<.0001$ \\
\hline Left atrial diameter $(\mathrm{cm})$ & 477 & $2.9(2.5-3.3)$ & 73 & $2.7(2.4-3.0)$ & .002 \\
\hline Lateral E/e' & 476 & $6.4(5.5-7.4)$ & 73 & $6.1(5.4-7.0)$ & .036 \\
\hline FEV1/FVC (\%) & 156 & $84(80-89)$ & 34 & $85(83-90)$ & .30 \\
\hline \multicolumn{6}{|l|}{ Laboratory tests } \\
\hline Oxygen saturation (\%) & 472 & $98(97-99)$ & 71 & $99(99-100)$ & $<.0001$ \\
\hline Asparate aminotransferase(U/L) & 480 & $42(31-54)$ & 75 & $21(17-29)$ & $<.0001$ \\
\hline Total bilirubin $(\mu \mathrm{mol} / \mathrm{L})$ & 480 & $37.6(23.9-56.4)$ & 75 & $8.6(5.1-12.0)$ & $<.0001$ \\
\hline Lactate dehydrogenase $(\mathrm{U} / \mathrm{L})$ & 437 & $398(287-561)$ & 73 & $180(152-209)$ & $<.0001$ \\
\hline NT-proBNP (ng/L) & 456 & $85(47-155)$ & 68 & $36(20-48)$ & $<.0001$ \\
\hline
\end{tabular}

Abbreviations: FEV1/FVC, forced expiratory volume in 1 minute to forced vital capacity ratio. ${ }^{*}$ eGFR (estimated glomerular filtration rate) $=0.413 \times$ (height in $\mathrm{cm} / \mathrm{creatinine} \mathrm{in} \mathrm{mg} / \mathrm{dL}$ ). 
18 (3.6\%), $\mathrm{Hb} \mathrm{S} \beta^{0}$-thalassemia in 9 (1.8\%), and other genotypes including $\mathrm{Hb} \mathrm{SD}_{\text {Los Angeles }}$ and $\mathrm{Hb} \mathrm{SO}$ Arab 7 (1.4\%). The SCD patients and control subjects are compared in Table 1. The BMI, systemic blood pressure, and oxygen saturation were lower in the SCD patients, while TRV and LVIDD $z$ score were higher. Among laboratory tests, creatinine and hemoglobin were lower in the SCD patients while neutrophils, reticulocytes, ferritin, AST, total bilirubin, $\mathrm{LDH}$ and NT-proBNP were higher. Twenty four percent of SCD patients vs $19 \%$ of healthy non-SCD controls had a history of asthma. Blood eosinophil counts were significantly higher in subjects with history of asthma (mean $0.43 \times 10^{9}$ per liter vs $0.32 \times 10^{9}$ per liter, $P=.022$ ) and, in the subgroup of participants with pulmonary function tests $(\mathrm{N}=190)$, FEV1/FVC was significantly lower in subjects with history of asthma (median 0.82 vs $0.86, P<.001$ ).

\subsection{Definition of elevated TRV in SCD patients}

Most studies of children and adolescents with SCD have defined an elevated TRV to be $\geq 2.5 \mathrm{~m} /$ second, $^{25-29}$ but this cut-off represents $2 \mathrm{SD}$ above the mean value in adult rather than pediatric non-SCD controls. ${ }^{30}$ For the present study, we performed echocardiograpy in 75 control children without SCD, 67 of whom had a measurable TRV. The control children and adolescents were studied during the same time period as the SCD subjects and TRV was determined using the same equipment and by the same investigators. As previously published in a subgroup of the PUSH study, ${ }^{8}$ we used TRV values greater than 2 SD above the mean in the control subjects to define elevated TRV in patients with SCD. The mean \pm 2 SD TRV in the control subjects was $2.1 \pm 0.5 \mathrm{~m} /$ second. Therefore, we defined elevated TRV to be $\geq 2.7 \mathrm{~m} /$ second. Twenty-three (4.9\%) of the SCD subjects had an elevated TRV at baseline using this definition.

\subsection{Serum ferritin in SCD patients}

The serum ferritin concentration in SCD patients ranged from $7-12,700 \mathrm{ng} / \mathrm{mL}$. In linear regression analysis of serum ferritin in the

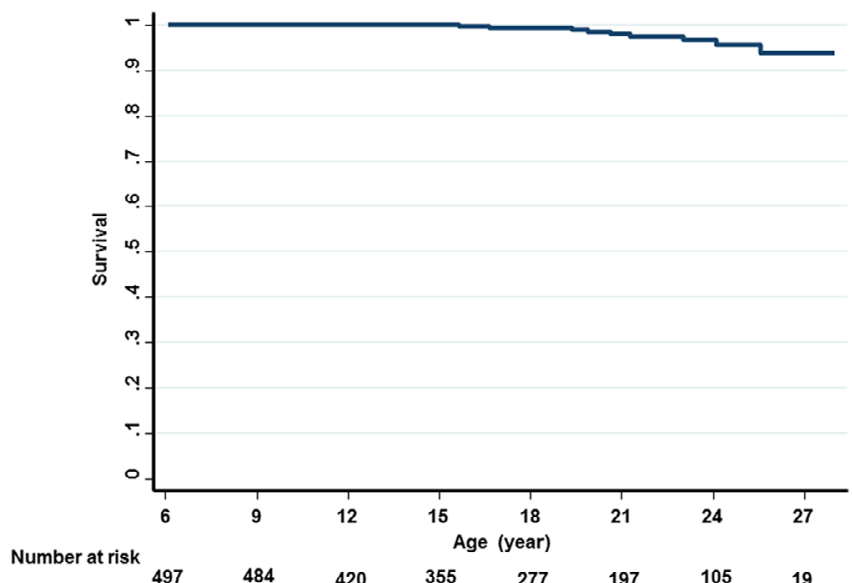

FIGURE 1 Kaplan-Meier estimated survival by age of follow-up [Color figure can be viewed at wileyonlinelibrary.com]

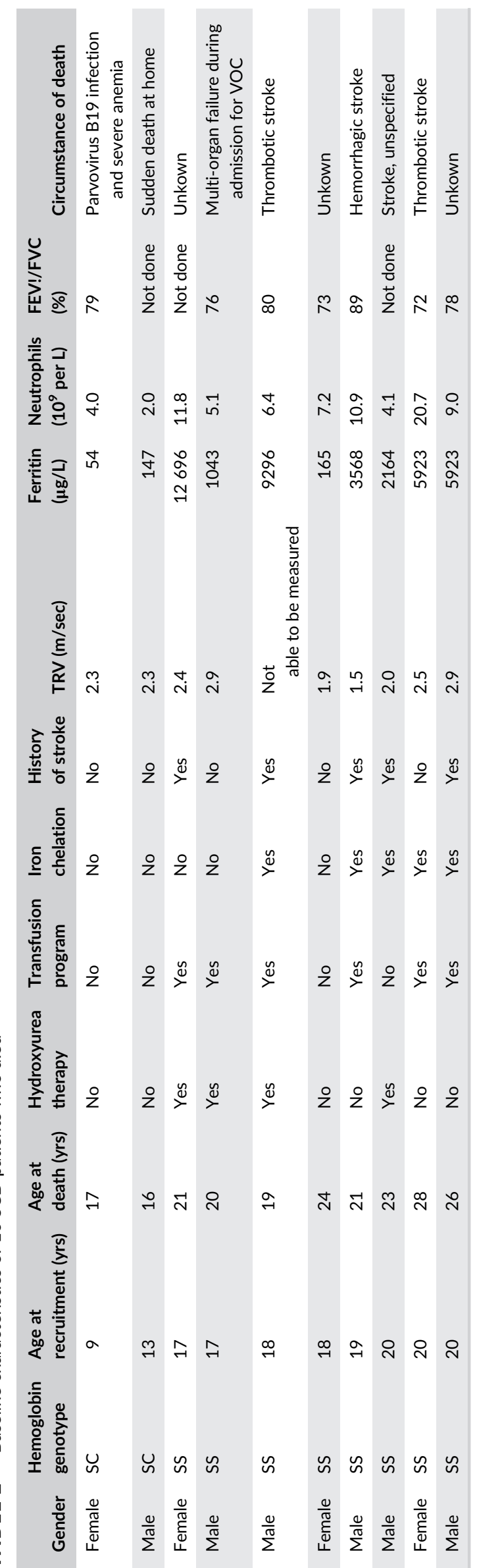


PUSH data set, transfusion history, absolute granulocyte count and the liver function test, ALT, accounted for $56 \%$ of the variation in serum ferritin. Transfusion history reflecting the iron burden of transfused red blood cells had the strongest independent relationship with higher serum ferritin concentration (partial $r=0.61, p<0.000001$ ). Higher absolute granulocyte count reflecting inflammation (partial $r=$ 0.17, $p=0.000006$ ) and higher ALT reflecting hepatocellular dysfunction (partial $r=0.11, p=0.003$ ) also had significant independent relationships with serum ferritin concentration.

\subsection{Estimated survival and causes of death in SCD patients}

Hydroxyurea was prescribed for $36.7 \%$ of the SCD subjects at baseline and $14.3 \%$ were on a chronic transfusion program. The mean corpuscular volume (median $92 \mathrm{fL}$ vs $81 \mathrm{fL} ; P<.001$ ) was significantly greater and the absolute neutrophil count (median $4.2 \times 10 / \mathrm{L}$ vs $4.8 \times 10^{9} / L ; P=.03$ ) was significantly lower in patients receiving hydroxyurea, suggesting compliance with the regimen at baseline. A history of stroke was obtained in 52 patients with a median age of 16 years (range 4-20 years); 29 (55.8\%) were on a chronic transfusion program and 21 (40.4\%) were on hydroxyurea therapy. This history of stroke seems high compared to the Dallas newborn cohort ${ }^{2}$ and the Cooperative Study of Sickle Cell Disease Cohort, ${ }^{31}$ possibly reflecting that our study was conducted at tertiary care centers where patients with special management needs are referred. There was a history of recurrent acute chest syndrome in 73 of the patients, 41 (56.2\%) of whom were treated with hydroxyurea at baseline.

The median follow up was 88 months (interquartile range 78-95 months). Ten of 497 patients (2.0\%) died during the follow-up period. Eight had hemoglobin SS and two had hemoglobin SC. The median age at the time of death was 21 years (range 16-28 years). The overall survival at 18 years of age was $99 \%$ (95\% Cl: $98 \%-99 \%)$

TAB LE 3 Relationship of baseline medical history with death. P values were calculated from log rank test for equality of survival

\begin{tabular}{|c|c|c|c|c|c|}
\hline & $\mathbf{N}$ & Alive & $\mathbf{N}$ & Died & $P$ (log rank test) \\
\hline Chronic transfusion program, no. (\%) & 479 & $64(13.4 \%)$ & 10 & $6(60.0 \%)$ & $<.001^{\mathrm{a}}$ \\
\hline History of stroke, no. (\%) & 482 & $47(9.8 \%)$ & 10 & $5(50.0 \%)$ & $.001^{\mathrm{a}}$ \\
\hline History of asthma, no (\%) & 483 & $113(23.4 \%)$ & 10 & $6(60.0 \%)$ & $.009^{a}$ \\
\hline $3+$ Severe pain episodes past year, no. (\%) & 487 & $91(18.6 \%)$ & 10 & $5(50.0 \%)$ & $.013^{\mathrm{a}}$ \\
\hline History of ACS or pneumonia, no (\%) & 482 & 232 (48.1\%) & 10 & $7(70.0 \%)$ & .17 \\
\hline Hemoglobin SS genotype, no (\%) & 487 & 364 (74.7\%) & 10 & $8(80.0 \%)$ & .70 \\
\hline Male gender, no (\%) & 487 & $248(50.9 \%)$ & 10 & $6(60.0 \%)$ & .64 \\
\hline Hydroxyurea treatment, no (\%) & 483 & $177(36.6 \%)$ & 10 & $4(40.0 \%)$ & .88 \\
\hline
\end{tabular}

${ }^{a}$ Significant after adjusting for multiple hypothesis testing using False Discovery Rate $<0.05$.

TAB LE 4 Relationship of baseline TRV and other biomarkers with death. $P$ values were calculated from log rank test for equality of survival

\begin{tabular}{|c|c|c|c|c|c|}
\hline & $\mathbf{N}$ & Alive & $\mathrm{N}$ & Died & $P(\log$ rank test) \\
\hline TRV $\geq 2.7$ m/sec, no. (\%) & 462 & $21(4.6 \%)$ & 10 & $2(20.0 \%)$ & $.012^{\mathrm{a}}$ \\
\hline Ferritin $\geq 2000 \mu \mathrm{g} / \mathrm{L}$, no. (\%) & 410 & $32(7.8 \%)$ & 10 & $6(60.0 \%)$ & $<.001^{\mathrm{a}}$ \\
\hline Absolute neutrophils $\geq 10 \times 10^{9}$ per L, no. (\%) & 468 & $37(7.9 \%)$ & 10 & $3(30.0 \%)$ & $.018^{a}$ \\
\hline NT-proBNP $\geq 160$ (ng/L), no (\%) & 446 & $103(23.1 \%)$ & 10 & $5(50.0 \%)$ & .044 \\
\hline Oxygen Saturation $\leq 95 \%$, no (\%) & 462 & $67(14.5 \%)$ & 10 & $3(30.0 \%)$ & .24 \\
\hline Systolic blood pressure > 115 mm Hg, no. (\%) & 470 & 165 (35.1\%) & 10 & $4(40 \%)$ & .72 \\
\hline Hemolytic component* over the mean, no. (\%) & 403 & $206(51.1 \%)$ & 10 & $5(50 \%)$ & .83 \\
\hline Left atrial diameter $\geq 3.68 \mathrm{~cm}$, no. (\%) & 457 & 52 (11.4\%) & 10 & $0(0 \%)$ & .23 \\
\hline Lateral E/e', $\geq 8.84$ no. (\%) & 454 & $36(7.9 \%)$ & 10 & $0(0 \%)$ & .37 \\
\hline
\end{tabular}

Abbreviations: eGFR, estimated glomerular filtration rate; NT-proBNP, N-terminal-prohormone B-type natriuretic peptide; TRV, Tricuspid regurgitation velocity.

${ }^{\text {a }}$ Significant after adjusting for multiple hypothesis testing using False Discovery Rate $<0.05$.

bPrincipal component 1 of reticulocyte count, LDH, AST and total bilirubin. 
and at age 25 years was $94 \%$ (95\% Cl: $87 \%-97 \%$ ) (Figure 1). The baseline age, age of death and cause of death in the 10 patients who died are summarized in Table 2. The causes of death in the hemoglobin SS patients were de novo stroke in one, recurrent stroke in three, multiorgan failure in one and unknown in three. The causes of death in the hemoglobin SC patients were parvovirus B19 infection in one and sudden death at home in one. Seven of the patients who eventually died were on a chronic transfusion program and/or received treatment with hydroxyurea at the time of enrollment.

\section{5 | Relationship of baseline medical history to death in SCD patients}

The prevalence of baseline medical history variables according to death status are shown in Table 3. Older age, a chronic transfusion program, a history of stroke, a history of asthma and $3+$ severe pain episodes in the past year were the strongest baseline medical history variables associated with increased risk of death. As expected there was a high degree of overlap among patients on a chronic transfusion program and those with a history of stroke: $41.7 \%$ of the patients on a chronic transfusion program had a history of stroke vs $5.6 \%$ of those not on such a program. Hemoglobin SS genotype and baseline hydroxyurea treatment status were not significantly associated with mortality in this cohort.

\section{6 | Relationship of baseline TRV to risk of death in SCD patients}

Baseline TRV $\geq 2.7 \mathrm{~m} / \mathrm{second}$ was observed in $20.0 \%$ of the patients who died vs $4.6 \%$ of survivors $(P=0.012$ by the log rank test for equality of survival) (Table 4). Death occurred in two (8.7\%) of 23 patients with TRV $\geq 2.7 \mathrm{~m} /$ second compared to eight $(1.8 \%)$ of 449 patients with lower TRV values.

\section{7 | Relationship of other biomarkers with death in SCD patients}

Additional biomarkers associated with mortality were ferritin $\geq 2000 \mu \mathrm{g} / \mathrm{L}, \quad$ FEV1/FVC $<0.80$ and absolute neutrophil count $\geq 10 \times 10^{9}$ per $L$ (Table 4). Death occurred in six (15.8\%) of 38 patients with ferritin $\geq 2000 \mu \mathrm{g} / \mathrm{L}$ vs four (1.1\%) of 382 patients with lower ferritin values $(P<.001$ by the log rank test for survival). The FEV1/FVC ratio was determined in a subset of 156 patients. Death occurred in 5 (15.2\%) of 33 patients with FEV1/FVC $<0.80$ vs five $(4.1 \%)$ of 123 patients with higher FEV1/FVC values $(P<.001)$. Death occurred in three (7.5\%) of 40 patients with absolute neutrophil count $\geq 10 \times 10^{9} / \mathrm{L}$ vs seven (1.6\%) of 428 patients with lower neutrophil counts $(P=.018)$. Left atrial diameter, lateral $E / e^{\prime}$, LVIDD z-score, NT-proBNP and a hemolytic component were not significantly associated with mortality in these analyses.

\section{8 $\quad$ Relationship of baseline variables with the prognostic biomarker categories}

The strongest association of TRV $\geq 2.70 \mathrm{~m} /$ second was with a high degree of hemolysis as shown by the hemolytic component $(P<.001)$. The strongest associations of ferritin $\geq 2000 \mu \mathrm{g} / \mathrm{L}$ were with older age, a chronic transfusion program, a history of stroke, and an elevated neutrophil count $(P<.001)$. FEV/FVC $<0.8$ was associated with a history of asthma $(P<.001)$ and a higher eosinophil count $(P=.006)$. The strongest associations of neutrophil $\geq 10 \times 10^{9} / \mathrm{L}$ were with a higher degree of hemolysis as reflected in the hemolytic component, an elevated serum ferritin, and a chronic transfusion program $(P<.001)$.

\section{4 | DISCUSSION}

In this report we describe certain biomarkers associated with mortality, predominantly after transition to adulthood, in a cohort of children, adolescents and young adults with SCD who were followed prospectively in the Pulmonary Hypertension and the Hypoxic Response in SCD (PUSH) study. Stroke was the cause of death in four of 10 cases and in four of seven in whom the cause of death was known. There was a history of previous stroke in three of the four who died of stroke. Three of the four patients who died of stroke were on a chronic transfusion program and two of the three with a past history of stroke were on a chronic transfusion program. Baseline historical variables that were significantly associated with death over a median of almost 7 years of observation of this cohort included a chronic blood transfusion program, a history of stroke, older age, and histories of asthma and three or more severe pain episodes in the past year.

In the PUSH cohort we were particularly interested in biomarkers of mortality, with a focus on the TRV. The echocardiograpydetermined TRV is considered to be a valid estimate for the systolic pulmonary artery pressure. ${ }^{32,33}$ An elevated TRV can reflect pulmonary arterial hypertension or an increased pulmonary wedge pressure secondary to pulmonary venous hypertension or cardiac diastolic dysfunction as reflected in the echocardiogram parameters, left atrial diameter and the lateral E/e' ratio. ${ }^{34}$ The TRV, left atrial diameter and lateral $E / \mathrm{e}^{\prime}$ were all increased in the SCD patients in this study, as shown in Table 1. A number of studies have defined an elevated TRV to be values $\geq 2.5 \mathrm{~m} /$ second, which is more than $2 \mathrm{SD}$ above the mean in non-SCD adult controls, and have reported that an elevated TRV by this definition is associated with increased mortality in SCD adults. ${ }^{30,35-37}$ Some studies have found that a higher TRV cut-off of $3.0 \mathrm{~m} / \mathrm{second}$ is more strongly associated with mortality than the $2.5 \mathrm{~m} /$ second cut-off. $^{38,39}$ The definition of elevated TRV of $\geq 2.5 \mathrm{~m} /$ second has been adopted for studying children with SCD, ${ }^{25-29}$ although it is not clear that the same definition of elevated TRV would apply to both adults and children. The PUSH study enrolled a non-SCD control group contemporaneous with the SCD patients, and we utilized this control group to define an elevated TRV to be $\geq 2.7 \mathrm{~m} /$ second, or more than $2 \mathrm{SD}$ above the mean in non-SCD 
controls. The TRV values in this range were found in $4.9 \%$ of the SCD patients and proved to be significantly associated with death. An elevated hemolytic rate was the strongest baseline variable associated with $T R V \geq 2.70 \mathrm{~m} /$ second in the present study. Left atrial diameter and lateral $\mathrm{E} / \mathrm{e}^{\prime}$ did not have significant positive associations with TRV $\geq 2.70 \mathrm{~m} /$ second.

Three additional biomarkers measured at baseline proved to be even more significantly associated with mortality, namely serum ferritin $\geq 2000 \mu \mathrm{g} / \mathrm{L}$ (found in $9.1 \%$ of the patients), FEV1/FVC $<0.8$ (found in $21.2 \%$ of the patients), and absolute neutrophils $\geq 10^{9} / \mathrm{L}$ (found in $8.4 \%$ of the patients). The serum ferritin was $\geq 300 \mu \mathrm{g} / \mathrm{L}$, the upper limit of the reference range in adults, in $38.8 \%$ of the SCD patients in this study and it was $\geq 2000 \mu \mathrm{g} / \mathrm{L}$ in $9.1 \%$ of them. Serum ferritin is an indirect indicator of iron stores ${ }^{40}$ that increases in relation to the amount of blood transfused in sickle cell disease and other conditions. ${ }^{41-43}$ Serum ferritin also increases with inflammation or with hepatocellular damage in the absence of increased iron stores. ${ }^{44}$ In sickle cell anemia patients that elevated serum ferritin concentration reflects increased iron stores because of the frequency of blood transfusions for non-blood loss indications. ${ }^{41}$ In the present study, $71 \%$ of subjects with ferritin $\geq 2000 \mu \mathrm{g} / \mathrm{L}$ were on a chronic transfusion program while $10 \%$ of subjects with a lower serum ferritin were on such a program. Overall in the PUSH cohort, serum ferritin appears to be a composite marker that reflects increased iron stores related to blood transfusions, the presence of inflammation (independent relationship with absolute neutrophil count), and the potential organ toxicity of iron overload (independent relationship with increased ALT).

Low FEV1/FVC is a marker of airway obstruction that affects about one in five children with SCD. ${ }^{13,45}$ Reduction in lung growth, ${ }^{46}$ higher hemolysis ${ }^{13}$ and/or anemia, ${ }^{47}$ and increased pulmonary capillary blood volume ${ }^{48}$ may contribute to airway obstruction in SCD children. A history of asthma and higher blood eosinophil counts were associated with a low FEV1/FVC ratio in the present study, consistent with a potential allergic component as well. Our present observation of a relationship between low FEV1/FVC ratio and death is in contrast to another recent study, ${ }^{45}$ but is consistent with reports that measures of lower airway obstruction are associated with more frequent hospitalizations for pain or acute chest syndrome in children with $\mathrm{SCD}^{49}$ and with higher mortality in adults with SCD. ${ }^{35}$

In SCD, intravascular hemolysis, free heme, inflammation and ischemia-reperfusion injury accelerate neutrophil activation and binding to red bloods, platelets and endothelium. ${ }^{50-52}$ Neutrophil activation is believed to play an important role in vaso-occlusive crisis. ${ }^{53}$ In our study, a neutrophil count $\geq 10 \times 10^{9} \mathrm{~L}$ was a significant prognostic factor of mortality, and markers of hemolysis and iron overload were associated with higher neutrophil count.

Hydroxyurea use at baseline was not significantly different between the patients who died and survived in the PUSH study. Although lower neutrophil count and higher mean corpuscular volume suggested compliance with hydroxyurea at baseline, we did not evaluate adherence to hydroxyurea therapy during the study. Other limitations are that only one TRV measurement was made at inclusion into the study, that the cohort was recruited starting at age 3 years and the mortality rate reflects this characteristic of the study, that the exact cause of death was not known for all of the subjects who died, and that we did not focus on certain potential risk factors for mortality, such as a past history of splenic sequestration and hypercoagulation. It would have been ideal to follow the PUSH cohort for a longer period of time but we were unable to secure funding to do so.

In summary, the estimated survival of the PUSH cohort of children, adolescents and young adults with SCD was $99 \%$ to 18 years and this declined to $94 \%$ at 25 years. Stroke was the most common cause of death. Elevated systolic pulmonary artery pressure as reflected in TRV $\geq 2.7 \mathrm{~m} / \mathrm{second}$, high serum ferritin concentration, low FEV1/FVC and high neutrophil count were biomarkers of increased risk of death, predominantly after transition to adulthood. These biomarkers are easily obtainable and potentially can help identify patients in need of novel new therapies as well as established approaches such as the use of hydroxyurea to prevent vaso-occlusive complications, the need for blood transfusions and the use of iron chelation therapy for iron overload.

\section{CONFLICT OF INTEREST}

None to report.

\section{AUTHOR CONTRIBUTIONS}

VRG and MN performed the statistical analysis. OLC, MTG, GJK, VRG and CPM designed the study. MA, AC, OLC, DSD, GE, ND, VRG, LLJ, CPM, SN, SR, CS and JGT collected data. All authors participated in writing the manuscript and approved it.

\section{ORCID}

Deepika S. Darbari (D) https://orcid.org/0000-0002-0698-2936 Caterina P. Minniti (D) https://orcid.org/0000-0002-7059-2959 Gregory J. Kato (D) https://orcid.org/0000-0003-4465-3217 Andrew Campbell (iD https://orcid.org/0000-0002-8829-0043 James G. Taylor VI (D) https://orcid.org/0000-0002-4421-1809 Sergei Nekhai (D) https://orcid.org/0000-0003-0744-7887 Victor R. Gordeuk (D) https://orcid.org/0000-0003-4725-7295

\section{REFERENCES}

1. Le PQ, Gulbis B, Dedeken L, et al. Survival among children and adults with sickle cell disease in Belgium: benefit from hydroxyurea treatment. Pediatr Blood Cancer. 2015;62(11):1956-1961.

2. Quinn $C T$, Rogers $Z R$, Buchanan GR. Survival of children with sickle cell disease. Blood. 2004;103(11):4023-4027.

3. Quinn CT, Rogers ZR, McCavit TL, Buchanan GR. Improved survival of children and adolescents with sickle cell disease. Blood. 2010;115 (17):3447-3452.

4. Powars DR, Chan LS, Hiti A, Ramicone E, Johnson C. Outcome of sickle cell anemia: a 4-decade observational study of 1056 patients. Medicine. 2005;84(6):363-376.

5. van der Plas EM, van den Tweel XW, Geskus RB, et al. Mortality and causes of death in children with sickle cell disease in The Netherlands, before the introduction of neonatal screening. Br J Haematol. 2011; 155(1):106-110.

6. Telfer $\mathrm{P}$, Coen $\mathrm{P}$, Chakravorty $\mathrm{S}$, et al. Clinical outcomes in children with sickle cell disease living in England: a neonatal cohort in East London. Haematologica. 2007;92(7):905-912. 
7. Couque N, Girard D, Ducrocq R, et al. Improvement of medical care in a cohort of newborns with sickle-cell disease in North Paris: impact of national guidelines. Br J Haematol. 2016;173(6):927-937.

8. Minniti CP, Sable C, Campbell A, et al. Elevated tricuspid regurgitant jet velocity in children and adolescents with sickle cell disease: association with hemolysis and hemoglobin oxygen desaturation. Haematologica. 2009;94(3):340-347.

9. Gordeuk VR, Campbell A, Rana S, et al. Relationship of erythropoietin, fetal hemoglobin, and hydroxyurea treatment to tricuspid regurgitation velocity in children with sickle cell disease. Blood. 2009;114: 4639-4644.

10. Campbell A, Minniti CP, Nouraie M, et al. Prospective evaluation of haemoglobin oxygen saturation at rest and after exercise in paediatric sickle cell disease patients. Br J Haematol. 2009;147(3): 352-359.

11. Dham N, Ensing G, Minniti C, et al. Prospective echocardiography assessment of pulmonary hypertension and its potential etiologies in children with sickle cell disease. Am J Cardiol. 2009;104(5): 713-720.

12. Nouraie M, Reading NS, Campbell A, et al. Association of G6PD with lower haemoglobin concentration but not increased haemolysis in patients with sickle cell anaemia. Br J Haematol. 2010;150(2): 218-225.

13. Arteta M, Campbell A, Nouraie M, et al. Abnormal pulmonary function and associated risk factors in children and adolescents with sickle cell anemia. J Pediatr Hematol Oncol. 2014;36(3):185-189.

14. Fung EB, Harmatz PR, Milet M, et al. Disparity in the management of iron overload between patients with sickle cell disease and thalassemia who received transfusions. Transfusion. 2008;48(9):19711980.

15. Labbe G, Merlin E, Kauffman C, Fauquert JL, Heraud MC, Labbe A. The role of lung volume measurements by plethysmography in the follow-up of asthma in children. Rev mal Respir. 2010;27(1):42-48.

16. Galant SP, Nickerson B. Lung function measurement in the assessment of childhood asthma: recent important developments. Curr Opin Allergy Clin Immunol. 2010;10(2):149-154.

17. Weitzman M. Diagnostic utility of white blood cell and differential cell counts. Am J Dis Child. 1975;129(10):1183-1189.

18. Silver MA, Maisel A, Yancy CW, et al. BNP Consensus Panel 2004: a clinical approach for the diagnostic, prognostic, screening, treatment monitoring, and therapeutic roles of natriuretic peptides in cardiovascular diseases. Congest Heart Fail. 2004;10(5 Suppl 3):1-30.

19. Takatsuki S, Ivy DD, Nuss R. Correlation of N-terminal fragment of B-type natriuretic peptide levels with clinical, laboratory, and echocardiographic abnormalities in children with sickle cell disease. J Pediatr. 2012;160(3):428-433.e1.

20. Niss O, Fleck R, Makue F, et al. Association between diffuse myocardial fibrosis and diastolic dysfunction in sickle cell anemia. Blood. 2017;130(2):205-213.

21. Machado RF, Hildesheim M, Mendelsohn L, Remaley AT, Kato GJ, Gladwin MT. NT-pro brain natriuretic peptide levels and the risk of death in the cooperative study of sickle cell disease. $\mathrm{Br} J$ Haematol. 2011;154(4):512-520.

22. Rackoff WR, Kunkel N, Silber JH, Asakura T, Ohene-Frempong K. Pulse oximetry and factors associated with hemoglobin oxygen desaturation in children with sickle cell disease. Blood. 1993;81(12): 3422-3427.

23. Kidney Disease: Improving Global Outcomes (KDIGO) CKD Work Group. KDIGO clinical practice guideline for the evaluation and management of chronic kidney disease. Kidney Int Suppl. 2013;3:1-150.

24. Ingelfinger JR. Clinical practice. The child or adolescent with elevated blood pressure. N Engl J Med. 2014;370(24):2316-2325.

25. Yates AM, Joshi VM, Aygun B, et al. Elevated tricuspid regurgitation velocity in congenital hemolytic anemias: prevalence and laboratory correlates. Pediatr Blood Cancer. 2019;66(7):e27717.
26. Allen KY, Jones S, Jackson T, et al. Echocardiographic Screening of Cardiovascular Status in Pediatric Sickle Cell Disease. Pediatr Cardiol. 2019;40(8):1670-1678.

27. Peter ID, Asani MO, Abdullahi SU, Aliyu I, Obaro SK, Bode-Thomas F. Pulmonary hypertension and right ventricular function in Nigerian children with sickle cell anaemia. Trans R Soc Trop Med Hyg. 2019;113 (8):489-496.

28. Dubert M, Elion J, Tolo A, et al. Degree of anemia, indirect markers of hemolysis, and vascular complications of sickle cell disease in Africa. Blood. 2017;130(20):2215-2223.

29. Forrest S, Kim A, Carbonella J, Pashankar F. Proteinuria is associated with elevated tricuspid regurgitant jet velocity in children with sickle cell disease. Pediatr Blood Cancer. 2012;58(6):937-940.

30. Gladwin MT, Sachdev V, Jison ML, et al. Pulmonary hypertension as a risk factor for death in patients with sickle cell disease. N Engl J Med. 2004;350(9):886-895.

31. Ohene-Frempong K, Weiner SJ, Sleeper LA, et al. Cerebrovascular accidents in sickle cell disease: rates and risk factors. Blood. 1998;91 (1):288-294.

32. McQuillan BM, Picard MH, Leavitt M, Weyman AE. Clinical correlates and reference intervals for pulmonary artery systolic pressure among echocardiographically normal subjects. Circulation. 2001;104(23): 2797-2802.

33. Pyxaras SA, Pinamonti B, Barbati G, et al. Echocardiographic evaluation of systolic and mean pulmonary artery pressure in the follow-up of patients with pulmonary hypertension. Eur J Echocardiography. 2011;12(9):696-701.

34. Gordeuk VR, Castro OL, Machado RF. Pathophysiology and treatment of pulmonary hypertension in sickle cell disease. Blood. 2016;127(7): 820-828.

35. Chaturvedi S, Labib Ghafuri D, Kassim A, Rodeghier M, DeBaun MR. Elevated tricuspid regurgitant jet velocity, reduced forced expiratory volume in 1 second, and mortality in adults with sickle cell disease. Am J Hematol. 2017;92(2):125-130.

36. Cabrita IZ, Mohammed A, Layton M, et al. The association between tricuspid regurgitation velocity and 5-year survival in a North West London population of patients with sickle cell disease in the United Kingdom. Br J Haematol. 2013;162(3):400-408.

37. Damy T, Bodez D, Habibi A, et al. Haematological determinants of cardiac involvement in adults with sickle cell disease. Eur Heart J. 2016;37(14):1158-1167.

38. Upadhya B, Stacey RB, Ntim W, Knovich MA, Pu M. Echocardiography-derived tricuspid regurgitant jet velocity is an important marker for the progression of sickle-cell disease. Acta Haematol. 2014;132(2): 152-158.

39. Gladwin MT, Barst RJ, Gibbs JS, et al. Risk factors for death in 632 patients with sickle cell disease in the United States and United Kingdom. PLoS One. 2014;9(7):e99489.

40. Gordeuk VR, Reboussin DM, McLaren CE, et al. Serum ferritin concentrations and body iron stores in a multicenter, multiethnic primary-care population. Am J Hematol. 2008;83(8): 618-626.

41. Inati A, Musallam KM, Wood JC, Taher AT. Iron overload indices rise linearly with transfusion rate in patients with sickle cell disease. Blood. 2010;115(14):2980-2981. author reply 1-2.

42. Drasar E, Vasavda N, Igbineweka N, Awogbade M, Allman M, Thein SL. Serum ferritin and total units transfused for assessing iron overload in adults with sickle cell disease. Br J Haematol. 2012;157(5): 645-647.

43. Brittenham GM, Cohen AR, McLaren CE, et al. Hepatic iron stores and plasma ferritin concentration in patients with sickle cell anemia and thalassemia major. Am J Hematol. 1993;42(1):81-85.

44. Cullis JO, Fitzsimons EJ, Griffiths WJ, Tsochatzis E, Thomas DW. British Society for $\mathrm{H}$. Investigation and management of a raised serum ferritin. Br J Haematol. 2018;181(3):331-340. 
45. Cohen RT, Strunk RC, Rodeghier M, et al. Pattern of Lung Function Is Not Associated with Prior or Future Morbidity in Children with Sickle Cell Anemia. Ann Am Thorac Soc. 2016;13(8):1314-1323.

46. Field JJ, DeBaun MR, Yan Y, Strunk RC. Growth of lung function in children with sickle cell anemia. Pediatr Pulmonol. 2008;43(11):1061-1066.

47. Ozoh OB, Kalejaiye OO, Eromesele OE, Adelabu YA, Dede SK, Ogunlesi FO. Pulmonary dysfunction among adolescents and adults with sickle cell disease in Nigeria: implications for monitoring. Ann Thorac Med. 2019;14(4):269-277.

48. Wedderburn CJ, Rees D, Height S, et al. Airways obstruction and pulmonary capillary blood volume in children with sickle cell disease. Pediatr Pulmonol. 2014;49(7):724.

49. Boyd JH, DeBaun MR, Morgan WJ, Mao J, Strunk RC. Lower airway obstruction is associated with increased morbidity in children with sickle cell disease. Pediatr Pulmonol. 2009;44(3): 290-296.

50. Chen G, Zhang D, Fuchs TA, Manwani D, Wagner DD, Frenette PS. Heme-induced neutrophil extracellular traps contribute to the pathogenesis of sickle cell disease. Blood. 2014;123 (24):3818-3827.
51. Zhong $\mathrm{H}$, Yazdanbakhsh $\mathrm{K}$. Hemolysis and immune regulation. Curr Opin Hematol. 2018;25(3):177-182.

52. Gomez-Moreno D, Adrover JM, Hidalgo A. Neutrophils as effectors of vascular inflammation. Eur J Clin Invest. 2018;48(suppl 2): e12940.

53. Zhang D, Xu C, Manwani D, Frenette PS. Neutrophils, platelets, and inflammatory pathways at the nexus of sickle cell disease pathophysiology. Blood. 2016;127(7):801-809.

How to cite this article: Nouraie M, Darbari DS, Rana S, et al. Tricuspid regurgitation velocity and other biomarkers of mortality in children, adolescents and young adults with sickle cell disease in the United States: The PUSH study. Am J Hematol. 2020;95:766-774. https://doi.org/10.1002/ajh. $\underline{25799}$ 